\title{
CRIAÇÃO DE CONHECIMENTO NA LIDERANÇA E DESENVOLVIMENTO DE NOVOS LÍDERES
}

\author{
Uiliam Hahn Biegelmeyer ${ }^{1}$ \\ Universidade de Caxias do Sul \\ uiliam.hb@terra.com.br
}

Gissele Vacari $^{2}$

Flavia Camargo Bernardi ${ }^{3}$

MKF Soluções

flavia.bernardi@mkfsolucoes.com.br

Maria Emilia Camargo ${ }^{4}$

Universidade de Caxias do Sul

mariaemiliappga@gmail.com

Tania Craco ${ }^{5}$

Instituto Federal de Educação do Rio Grande do Sul

tcraco@yahoo.com.br

\begin{abstract}
Resumo
A liderança deve comunicar, motivar, delegar e planejar ações para que seus liderados apresentem comprometimento e demonstrem empenho em alcançar os objetivos propostos nesse sentido, o objetivo deste estudo foi identificar a percepção dos principais gestores da empresa, sobre a liderança e a importância da comunicação para atingir os resultados organizacionais, bem como identificar as possibilidades de aprimoramento e melhorias. Para tanto, a metodologia de pesquisa aplicada foi de caráter exploratório e abordagem qualitativa, por meio de um roteiro semiestruturado e entrevistas em profundidade conduzidas junto a seis gerentes. Os resultados da pesquisa evidenciam a necessidade de a empresa investir no desenvolvimento de líderes para aprimorar a comunicação interna e o processo de feedback, que foram citados pelos gestores como principais pontos de melhoria. Além disso, os resultados apontam para o desenvolvimento dos atuais e futuros líderes que atuam na organização.
\end{abstract}

Palavras-chave: Liderança. Feedback. Comunicação.

\section{KNOWLEDGE CREATION IN LEADERSHIP AND DEVELOPMENT OF NEW LEADERS}

\begin{abstract}
Leaders are supposed to communicate, motivate, delegate, and plan actions so that their subordinates may be committed and determined to reach the proposed goals. In this regard, this study aims to identify how the main administrators of the company, perceive leadership and the importance of communication in achieving the organizational results. Another purpose was to identify opportunities for improvement and enhancement. To this end, the research methodology used was the exploratory one along with qualitative approach by means of a semistructured plan and in-depth interviews held with six managers. The research showed that the company needs to invest in the development of leaders to improve internal communication and the feedback process, which are the main points of improvement. In addition, the results indicate the need to develop these leaders and the future leaders who act in the organization.
\end{abstract}

Keywords: Leadership. Feedback. Communication.

\footnotetext{
${ }^{1}$ Doutor em Administração.

${ }^{2}$ MBA em Gestão de Pessoas.

${ }^{3}$ Mestra em Administração.

${ }^{4}$ Doutora em Engenharia de Produção.

${ }^{5}$ Doutora em Administração.
} 
INOVAÇÃO

\section{INTRODUÇÃO}

O crescimento de uma empresa ocorre quando os gestores estão preparados para liderar, comunicar, motivar, delegar e planejar ações para que suas equipes demonstrem empenho e apresentem comprometimento em alcançar os objetivos da organização. O líder deve ter atitudes que sirvam como exemplo de excelência, fazendo com que seus liderados percebam isso e entendam que também precisam ser bons exemplos, com atitudes proativas e inovadoras.

Para Hunter (2004), a liderança é definida como a competência de incentivar as pessoas a atingirem um objeto comum a todos. O líder deve ser empático com os seus liderados, para que obtenha o empenho máximo de todos (HUNTER, 2004).

A liderança compreende a capacidade de mobilizar outras pessoas para concretizar uma visão, meta e/ou tarefa. Líderes conseguem com que outras pessoas façam o que precisa ser feito por meio do gerenciamento, da delegação combinada com outras ferramentas e ações para assegurar continuidade (CHARAN, 2008).

Para mobilizar os integrantes de uma equipe, um líder utiliza a comunicação, sendo que esta passa pelo conhecimento pessoal (entender e valorizar a si mesmo), conhecimento social (engajar e impor desafio aos outros), conhecimento de negócios (focar e mobilizar a sua organização) e conhecimento cultural (valorizar e tirar o proveito das diferenças culturais) (WALKER, 2015). Cabe ao líder utilizar todos os seus conhecimentos de modo a impactar positivamente as pessoas (WALKER, 2015).

Nesse sentido, o problema de pesquisa deste estudo consiste em compreender: qual é a percepção dos gestores da empresa Máquinas Ltda sobre a liderança e as necessidades de desenvolvimento de novos líderes? A partir dessa interrogativa e dos resultados do estudo, temse como intuito criar uma proposta de desenvolvimento dos gestores, preparando-os para atuarem como líderes.

Desta forma, o objetivo geral do estudo é identificar a percepção dos gestores sobre a liderança e a importância da comunicação para atingir os objetivos da empresa. Visando um melhor delineamento da pesquisa, o objetivo geral foi dividido nos seguintes objetivos específicos:

a) realizar a revisão teórica referente à liderança e à comunicação;

b) desenvolver entrevistas em profundidade com os gestores da empresa para identificar as principais dificuldades relacionadas à liderança;

c) elaborar uma proposta para o desenvolvimento das lideranças atuais e sucessoras. 
Cabe ressaltar que este tema foi definido a partir da análise dos resultados das pesquisas de clima organizacional realizadas na empresa no período de 2015 a 2017, que permitiram medir o envolvimento das lideranças com suas equipes de trabalho e o que pode ser desenvolvido para melhorar esta relação, consequentemente, gerando resultados mais satisfatórios para a organização. Perante a possibilidade de melhoria no processo de gestão, a proposta deste trabalho é a elaboração de um programa de lideranças com foco em resultados, contemplando não somente as pessoas que exercem cargo de liderança, bem como possíveis sucessores, para que esses estejam devidamente preparados quando assumirem a liderança dentro da organização.

O estudo contempla uma metodologia exploratória com abordagem qualitativa, por meio de estudo de caso único e entrevistas em profundidade realizadas com os gestores da organização. Para atingir os objetivos propostos no estudo, esse artigo está organizado da seguinte forma: inicialmente tem-se o referencial teórico, na sequência a metodologia aplicada à pesquisa e, por fim, as considerações finais.

\section{REFERENCIAL TEÓRICO}

\subsection{CONCEITOS DE LIDERANÇA}

O interesse em relação à liderança é tão antigo quanto às próprias pessoas. Talvez seja o tema mais discutido e detalhado no campo da gestão de uma empresa. A partir do momento em que duas pessoas encontram-se, uma delas automaticamente se dirige a interpretar o que está acontecendo e indica um rumo a seguir. Além disso, liderança é um tema intrigante (BERGAMINI, 2009; MELO, 2014; MELLO; ORTEGA, 2012).

Muitas pessoas pensam que reconhecem um líder quando o enxergam, porém a maioria das pessoas tem uma noção errada do que um líder realmente faz (CHARAN, 2008). Cohen e Fink (2003) elencaram algumas perguntas que o mundo espera por respostas: "De que é feito um bom líder? Quem pode ser um líder? É possível ensinar habilidades de liderança? Quais os limites da liderança?"

Da mesma forma, Mello e Ortega (2012) postulam que estabelecer o modelo ideal de liderança é um grande desafio para as organizações e, para isso, é necessário definir quais as habilidades necessárias para liderar, o que o líder pensa sobre si mesmo e o que os demais pensam sobre ele, como os líderes reagem à pressão por resultados, entre outros questionamentos que dependem de cada organização. 
Cabe ressaltar que nem sempre os gestores eficazes são líderes verdadeiros. A capacidade de liderar distingue gestores excelentes dos medianos e a liderança tem muita relação com o resultado das empresas. Para Bateman e Snell (2007), o sucesso das empresas depende do modelo de liderança e da aceitação dela pelos liderados.

As primeiras abordagens sobre liderança sustentavam que os líderes não eram produzidos, mas, como por herança genética, já nasciam líderes. Essa ideia foi descartada mais tarde por pesquisadores influenciados por escolas de pensamentos comportamentalistas, considerando que muitas características relacionadas à liderança podiam ser adquiridas (WAGNER; HOLLENBECK, 2009). A liderança não é uma competência nata, ela se desenvolve conforme as experiências de cada indivíduo (SOARES, 2015).

Liderar é a capacidade de influenciar as pessoas a deixarem de lado suas preocupações pessoais para apoiarem uma visão holística (BALDWIN; RUBIN; BOMMER, 2008). Líderes mais efetivos motivam as pessoas a desempenharem acima e além do dever para realçar o sucesso do grupo (BALDWIN; RUBIN; BOMMER, 2008).

Para ser um líder eficiente, faz-se necessário possuir diversas competências, sendo de extrema importância a habilidade de influenciar a equipe, modificando assim, as atitudes dos liderados (MOTTA, 1997).

Líderes eficientes e eficazes possuem forte senso de responsabilidade, tendência de completar tarefas, energia, persistência para atingir objetivos, propensão para assumir riscos, originalidade para solucionar problemas e, o mais importante, disposição para aceitar consequências da tomada de decisão e ação (COHEN; FINK, 2003).

Para Mello e Ortega (2012), o líder efetivo consegue assimilar a cultura da empresa e torná-la mais próspera. Outro ponto essencial é que o papel do líder aumentou e os líderes devem ter uma atuação sistêmica, com foco na maximização dos resultados e em gestão de pessoas.

De acordo com Cortella e Mussak (2016), em determinadas situações, considera-se um bom líder pela sua capacidade de comunicação, porém não é apenas isso que determina uma boa liderança. Um bom líder deve ser dotado de inteligência interpessoal e intrapessoal, ou seja, aquele que se esforça, organiza-se e estrutura-se para comunicar-se bem e consequentemente exercer uma boa liderança. Os autores ainda afirmam que nas organizações existem cargos de gerente, diretor, supervisor, superintendente, mas não de líder, embora muitas adotem essa denominação. Liderança não é um cargo, mas sim uma condição, um comportamento humano (CORTELLA; MUSSAK, 2016). 
Em complemento a isso, Selman (2010) ressalta que a liderança é um fenômeno social, mais um produto das pessoas que seguem o gestor do que daquelas que são reconhecidas e respeitadas como líderes, portanto, não há liderança sem o compromisso dos liderados. Entretanto, nenhuma definição para liderança é totalmente definitiva, por isso conceituá-la requer reflexões sobre diversas perspectivas.

Para Soares (2015) e Blanchard (2011), inicialmente em nível organizacional, a liderança possuía ênfase na realização de objetivos, foco no trabalho e era conceituada como uma forma de controle que impunha metas para a equipe atingir os objetivos da organização, não pensando nas pessoas que as executavam.

Em sua essência, liderar é praticar uma série de ações, sendo algumas programadas e outras espontâneas, com o intuito de comandar, conduzir, influenciar e inspirar pessoas ou grupos, para que trabalhem no sentido de alcançar resultados pessoais e profissionais satisfatórios por meio dos objetivos organizacionais (MADRUGA, 2014).

Consoante a isto, Maximiano (2011) descreve que liderança é o uso da influência não coercitiva para dirigir as atividades dos membros de um grupo e levá-los à realização de seus próprios objetivos.

A liderança é parte essencial do sucesso das organizações, pois é por meio dessa gestão que as metas e os objetivos são expostos entre todos os níveis hierárquicos. Através das características individuais dos colaboradores é possível atingir os desafios propostos. Quando os liderados identificam-se com o líder e enxergam coerência em suas atitudes, buscam os resultados de forma inconsciente. Quanto mais o líder for admirado por sua equipe, mais êxito ela terá e mais influente ele será (OLIVEIRA, 2010).

Para que a liderança seja eficaz e assertiva, o líder passa a receber suporte da área de gestão de pessoas e, para isso, é necessário que ela esteja atenta às mudanças no ambiente externo e organizacional (GIL, 2001).

Por sua vez, Maxwell (2011) complementa que o líder não tem receio de dividir o seu conhecimento com a equipe, assim como sabe reconhecer o trabalho de cada funcionário, está sempre presente, mostrando credibilidade, conforto e segurança na tarefa que está executando.

A confiança na equipe é extremamente importante ao se tratar de liderança, manter um bom relacionamento com os liderados transmitindo estabilidade, sendo severo e extrovertido na medida e hora certa. Segundo Maxwell (2011), a credibilidade de um líder começa com o sucesso pessoal e se confirma na iniciativa de ajudar sua equipe a alcançar sucesso também.

A liderança é importante para o sucesso da organização e para o bem-estar dos funcionários. Há cada vez mais evidências que sugerem que a liderança efetiva é uma das 
melhores fontes de vantagem competitiva que uma organização pode ter em relação aos seus concorrentes (BALDWIN; RUBIN; BOMMER, 2008).

Em resumo, a liderança pode ocorrer em qualquer momento ou lugar, independente do porte da organização, sendo que líderes exemplares adotam como práticas: traçar o caminho, inspirar uma visão compartilhada, desafiar o processo, capacitar os outros a agir e encorajar o ânimo (KOUZES; POSNER, 2008). Além disso, destaca-se a necessidade de o líder ter a plena consciência que primeiro precisa liderar a si mesmo, ter autoconhecimento, para depois liderar outras pessoas (MELLO; ORTEGA, 2012).

\subsection{COMUNICAÇÃO VERSUS LIDERANÇA}

Uma das principais alegações que se repete entre os funcionários de diversas equipes é a inadequada comunicação do líder, sendo que muitas vezes mantém um afastamento rotineiro, fazendo-se presente em encontros formais e com pautas pré-definidas (MELLO; ORTEGA, 2012).

A comunicação é muito importante para o sucesso gerencial. Pessoas que se comunicam bem costumam ser promovidas com maior rapidez e recebem mais e melhores oportunidades de trabalho do que as que não possuem boa comunicação. Essa comunicação afeta quase todos os aspectos do comportamento gerencial. Motivar, dar retorno, trabalhar em equipe ou liderar mudanças exigem habilidades efetivas de comunicação (BALDWIN; RUBIN; BOMMER, 2008).

Para Moscovici (2005), o desenvolvimento de competência interpessoal exige a aquisição e o aprimoramento de habilidades de comunicação para facilitar a compreensão. Estas competências devem ser treinadas e praticadas para obtenção de melhores resultados. As principais habilidades de comunicação são: a) paráfrase: dizer o que outro disse com suas próprias palavras. Envolve atenção, escuta ativa e empatia e tem como benefício o aumento da precisão da comunicação, a compreensão mútua e a percepção de como o outro vê as coisas; b) a descrição de comportamento: relatar ações pontuais e observáveis dos outros, sem fazer julgamentos ou generalizar seus motivos ou traços de personalidade. Para isso é preciso aprimorar a capacidade de observação; c) a verificação de percepção: dizer a sua percepção sobre o que o outro está sentindo, para verificar se existe a compreensão dos sentimentos do outro. Esta habilidade constitui uma das melhores formas de desenvolver a capacidade de empatia, em que observação acurada, a comparação com sentimentos já experimentados e a autocolocação no lugar do outro se conjugam, levando a compreensão mútua e a maior 
competência interpessoal para a vida em comum; d) descrição de sentimentos: identificar ou especificar sentimentos, seja por meio do nome do sentimento ou figuras de linguagem e ainda, impulso de ação o que corresponde ao processo de auto exposição que permite compartilhar com os outros seus sentimentos e pensamentos.

A comunicação é o pilar da liderança, é algo básico para o líder e nem sempre é a principal habilidade do mesmo. Para liderar é preciso ter a capacidade de transmitir uma mensagem clara, de modo a persuadir, inspirar e motivar seus seguidores. Isto não significa apenas habilidade com palavras, mas a capacidade de transformar ideias em mensagens convincentes. (MAXIMIANO, 2011).

Diante disso, ressalta-se que uma boa comunicação é elemento fundamental para o sucesso de uma excelente liderança. Os líderes não devem ter medo de expor suas ideias, apenas devem estar atentos para falar de forma a serem compreendidos, ou seja, de maneira objetiva e clara. (MAXIMIANO, 2011).

Para Brum (2017) é de responsabilidade do líder, não apenas informar os objetivos e a estratégia da empresa, mas também comunicar-se com a equipe de forma contínua para que ela esteja capacitada para executar e atingir os resultados.

Por outro lado, muitos líderes sentem-se desconfortáveis ao aproximar-se das pessoas com as quais trabalham, por isso, muitas vezes, precisam desenvolver-se para vencer essa barreira (MELLO; ORTEGA, 2012).

\subsection{COMPETÊNCIAS DA LIDERANÇA}

Competência compreende uma série de características que uma pessoa possui para realizar uma determinada atividade e/ou trabalho. Contempla conhecimentos, habilidades, experiências e valores no caso da liderança, as competências devem ser conhecidas, analisadas e avaliadas, traçando-se um perfil de pontos fortes e fracos (MELLO; ORTEGA, 2012).

Dessa forma, é possível inferir que liderar requer inúmeros conhecimentos, habilidades e atitudes para fazer com que os objetivos sejam atingidos, por meio de pessoas inspiradas. Conseguir retirar o que existe de melhor em cada membro da equipe, tendo como objetivo o resultado que é esperado pela organização.

A liderança é exercida todos os dias, em maior ou menor escala, dependendo do perfil de cada indivíduo e da situação em que se encontra. Diferentemente do que acontecia no passado, esse título não é concedido pela empresa, ou seja, a liderança não representa um cargo, mas sim, um papel a ser exercido (CORTELLA; MUSSAK, 2016).

P2P \& INOVAÇÃO, Rio de Janeiro, v. 7, n. 1, p. 205-226, set. 2020/fev. 2021. 
Baldwin, Rubin e Bommer (2008) afirmam que a liderança é fortalecida de acordo com a vivência de cada pessoa e que a busca por ela deve ser constante. Ainda para Cortella e Mussak (2016), o bom líder inspira, motiva e além de fazer com que as pessoas acreditem em si mesmas, consegue mais produtividade, não por regras ou imposições, mas por relacionamento e comprometimento. A liderança não pode mais ser exercida a partir de uma posição na hierarquia de comando e controle. O líder moderno precisa ter habilidade com pessoas, pois é por meio delas que são realizadas as ações que acontecem dentro e fora da empresa. Portanto, é importante estimular a motivação de seus liderados de maneira a abranger desde a satisfação pessoal até melhoria das condições de trabalho.

A partir de inúmeros estudos, Kouzes e Posner (2008) destacam que por meio de análises e de questionários, existem cinco práticas comuns exercidas em lideranças bemsucedidas:

Traçar o caminho: ser o exemplo do que você prega. Líderes exemplares sabem que devem servir de modelo comportamental do que esperam dos outros. Conquistar o direito e o respeito para liderar por meio do envolvimento e da ação direta, pois as pessoas seguem o líder em primeiro lugar, depois o plano estabelecido;

Inspirar uma visão compartilhada: os líderes devem engajar as pessoas e, para isso, devem compreender como os membros do grupo se relacionam, fazendo com que percebam que realmente entende as necessidades e interesses da equipe. A liderança é um diálogo, onde para obter o apoio, os líderes devem conhecer os sonhos, esperanças, aspirações, visões e valores de seus liderados;

Desafiar o processo: líderes devem sempre buscar oportunidades para inovar, crescer e melhorar. Os líderes devem estar atentos à capacidade da sua equipe de controlar as situações de desafio para que permaneça comprometida mesmo com possíveis mudanças. Os líderes estão em constante aprendizado, com seus erros e com seus acertos, também possibilitando que os demais façam o mesmo;

Capacitar os outros a agir: para que coisas extraordinárias aconteçam, os líderes devem capacitar os outros a agirem. Os líderes têm o papel de promover a colaboração e criar confiança, desenvolvendo o senso de equipe, engajando a todos para que o objetivo seja alcançado. Verdadeiros líderes não acumulam poder, mas o delega fortalecendo a capacidade de cada liderado em cumprir o que foi prometido;

Encorajar o ânimo: Atos sinceros de cuidado elevam o moral e fazem com que o grupo busque os objetivos com determinação. Reconhecer as conquistas e criar uma cultura de comemoração tem a capacidade de auxiliar a condução do grupo em tempos difíceis.

P2P \& INOVAÇÃO, Rio de Janeiro, v. 7, n. 1, p. 205-226, set. 2020/fev. 2021. 
O líder deve sempre dar o exemplo, ser o modelo para os integrantes da equipe, ser capaz de motivar e entusiasmar as pessoas, levando-as ao crescimento e desenvolvimento contínuo, também deve inspirar confiança aos liderados (MELLO; ORTEGA, 2012).

Uma das principais competências do líder é saber proporcionar feedbacks úteis e suficientes. Assim, como gestor, é importante considerar todas as causas potenciais de desempenho ruim, dar atenção quando os funcionários solicitarem feedback ou quiserem discutir questões relacionadas ao desempenho. Um líder que sabe a importância das pessoas proporciona feedbacks regulares e contínuos, resolvendo problemas imediatamente, prevenindo surpresas quando realizarem a avaliação de desempenho formal (BATEMAN; SNELL, 2007).

Para desenvolver as competências de liderança é importante estabelecer um modelo de aprendizagem organizacional, no qual os gestores possam praticar no mundo real, convertendo essa experiência em habilidade e senso crítico (CHARAN, 2008).

\section{METODOLOGIA DA PESQUISA}

Esse capítulo apresenta a metodologia aplicada no desenvolvimento da pesquisa, os tipos e métodos de pesquisa, as técnicas de coleta de dados e a análise dos dados.

\subsection{TIPO E MÉTODO DE PESQUISA}

A metodologia proposta para este estudo é de caráter exploratório e qualitativo, pois o mesmo investigou a liderança da empresa. Por meio do método de estudo de caso, analisou-se a percepção dos gestores da empresa, tendo como objetivo elaborar uma proposta de desenvolvimento de lideranças para os atuais líderes e seus possíveis sucessores.

Para Prodanov e Freitas (2013), método é um procedimento ou caminho para alcançar determinado fim e que o propósito da ciência é a busca pelo conhecimento. O método científico é um conjunto de procedimentos adotados com o propósito de atingir o conhecimento.

Assim, o estudo caracteriza-se como exploratório, sendo esse o tipo de pesquisa mais adequado, já que possibilita a exploração e a busca pelo entendimento sobre fenômenos pouco explorados. O estudo exploratório é caracterizado pela flexibilidade e versatilidade com respeito aos métodos (AAKER; KUMAR; DAY, 2007).

Referindo-se à pesquisa qualitativa, Roesch (2006) afirma que esta é indicada quando o autor busca uma análise completa e profunda dos dados coletados. O estudo qualitativo é interpretativo, é experiencial, é situacional e ainda, é personalístico. Quando é bem 


\section{ARTIGO}

INOVAÇÃo

desenvolvido traz à tona compreensões profissionais relacionadas à investigação (STAKE, 2011).

No que tange ao método, o mais adequado para esta pesquisa é o estudo de caso. Segundo Gil (2001), o estudo de caso consiste no estudo aprofundado e exaustivo de poucos objetivos, de maneira que permita o seu amplo e detalhado conhecimento. De acordo com o autor, este tipo de pesquisa também é utilizado com vários propósitos, destacando-se a exploração de condições reais, cujos limites não são bem conhecidos e a descrição das situações e do contexto no qual a investigação é realizada, além de serem formuladas e desenvolvidas hipóteses e teorias na visão de Yin (2010), o estudo de caso é utilizado quando o pesquisador tem pouco controle sobre os eventos.

Corroborando com essa visão, Prodanov e Freitas (2013) consideram que o estudo de caso consiste em coletar e analisar informações sobre determinado indivíduo, família, grupo ou comunidade, para estudar aspectos variados, de acordo com o assunto da pesquisa. Para o desenvolvimento são necessários alguns requisitos básicos, entre os quais, severidade, objetivação, originalidade e coerência.

Nessa mesma linha, Yin (2005) identifica o método de estudo de caso como uma investigação empírica que procura analisar um fenômeno contemporâneo dentro de seu contexto da vida real, especialmente quando os limites entre o fenômeno e o contexto não estão claramente definidos. Acevedo e Nohara (2007) enfatizam que o estudo de caso se caracteriza pela análise em profundidade de um objeto ou um grupo de objetos, podendo ser estes indivíduos ou organizações.

\subsection{TÉCNICAS DE COLETA DOS DADOS}

Para a obtenção de informações e dados, existem várias técnicas de coletas neste estudo, como a pesquisa foi exploratória, realizou-se a entrevista em profundidade, com base num roteiro semiestruturado, a qual foi realizada com os gerentes da organização.

O roteiro semiestruturado foi elaborado com base nos referenciais teóricos e passou pela avaliação e validação de dois especialistas em liderança durante o mês de janeiro de 2018. Além disso, foi realizado um pré-teste com um gestor da respectiva empresa. O pré-teste foi desenvolvido com um coordenador da área de produção. $\mathrm{O}$ intuito foi analisar o entendimento das questões e a necessidade de possíveis complementos. $\mathrm{O}$ entrevistado do pré-teste teve um bom entendimento, respondendo as questões sem dificuldade, compreendendo que as mesmas contemplam todos os itens necessários para o tema. 
Em geral, tanto os roteiros quanto os questionários passaram por um pré-teste. Durante o pré-teste verificou-se o entendimento das questões por parte dos entrevistados, se a ordem das questões estava de acordo, se não faltava complementação para que os objetivos do estudo pudessem ser atingidos (RUTTER; ABREU, 2003).

As entrevistas com os gestores foram conduzidas no período de 06 de fevereiro a 06 de março de 2018, sendo que, em média, demoraram noventa minutos para serem concluídas.

Conforme Marconi e Lakatos (2008), a entrevista é um encontro entre duas pessoas, a fim de que uma delas obtenha informações a respeito de determinado assunto, mediante uma conversação de natureza profissional. É um procedimento, utilizado na investigação social para coleta de dados ou também para ajudar no diagnóstico ou no tratamento de um problema social.

O método de entrevistas em profundidade é utilizado quando se deseja analisar as percepções individuais sobre determinado tema, sem haver interferências. Geralmente, o roteiro das entrevistas apresenta flexibilidade, pois podem surgir outras perguntas espontâneas durante o processo (RUTTER; ABREU, 2003).

\subsection{TÉCNICAS DE ANÁLISE DOS DADOS}

O estudo seguiu uma abordagem qualitativa e, após a coleta dos dados, foi realizada a análise de conteúdo. As entrevistas foram transcritas na íntegra a fim de evitar a perda de alguma informação e/ou detalhe importante para o desenvolvimento do estudo. Para Vergara (2000), a análise de conteúdo é considerada uma técnica para o tratamento de dados que visa identificar o que está sendo dito a respeito de determinado tema.

É por meio da análise que se procura verificar as relações existentes entre o fenômeno estudado e outros fatores, as quais podem ser estabelecidas em função de suas propriedades relacionais de causa e efeito, produtor-produto, de correlações, de análise de conteúdo, ou seja, os limites da validade dessas relações (MARCONI; LAKATOS, 2008).

Desta forma, o pesquisador, ao deparar-se com os inúmeros dados coletados, deve utilizar a técnica de análise de conteúdo que, segundo Roesch (2006), por meio das entrevistas e do exame dos mesmos, permite captar o nível de emoção dos respondentes, a maneira como organizam o mundo, seus pensamentos sobre o que está acontecendo, suas experiências e percepções básicas. Utilizando a análise de conteúdo, é possível encontrar palavras ou expressões chave dentro do texto, que contribuam para análise dos dados.

\section{ANÁLISE DOS DADOS}

P2P \& INOVAÇÃO, Rio de Janeiro, v. 7, n. 1, p. 205-226, set. 2020/fev. 2021. 
Para propor melhorias em algum processo é preciso coletar informações e após analisálas, para que seja possível identificar a necessidade de melhoria e como a mesma deve ser implantada. Dessa forma, o capítulo abordará a descrição das entrevistas juntamente com a análise qualitativa dos dados. A pesquisa foi realizada na empresa e contou com a participação dos gerentes que compõem o Quadro 1, conforme abaixo:

Quadro 1 - Perfil dos gestores entrevistados.

\begin{tabular}{|c|l|}
\hline ENTREVISTADO & \multicolumn{1}{c|}{ FORMAÇÃO E EXPERIÊNCIA } \\
\hline Entrevistado A & $\begin{array}{l}\text { Possui graduação em Administração de Empresas pela Universidade Luterana do Brasil. } \\
\text { Atualmente é responsável por uma divisão da área Comercial, ocupando o cargo de } \\
\text { Gerente Comercial. }\end{array}$ \\
\hline Entrevistado B & $\begin{array}{l}\text { Possui graduação em Engenharia Mecânica pela Fundação Armando Alvares Penteado } \\
\text { e especialização em administração industrial pela Fundação Vanzolini. Atualmente é } \\
\text { responsável pelas áreas de PCP e demais áreas fabris, ocupando o cargo de Gerente de } \\
\text { Produção. }\end{array}$ \\
\hline Entrevistado C & $\begin{array}{l}\text { Possui o curso técnico em mecânica pela Escola Técnica Federal - SP e graduação em } \\
\text { Engenharia Mecânica de Mogi das Cruzes. Atualmente é responsável por uma divisão } \\
\text { da área de Marketing, ocupando o cargo de Gerente de Marketing. }\end{array}$ \\
\hline Entrevistado D & $\begin{array}{l}\text { Graduando em Administração de Empresas pela Universidade de Caxias do Sul. } \\
\text { Atualmente é responsável por uma divisão da área Comercial, ocupando o cargo de } \\
\text { Gerente Comercial. }\end{array}$ \\
\hline Entrevistado E & $\begin{array}{l}\text { Possui graduação em Ciências Contábeis pela Universidade de Caxias do Sul e } \\
\text { Especialização em Controladoria, Finanças e Auditoria pela Universidade de Caixas do } \\
\text { Sul e Graduando em Direito pela mesma instituição. Atualmente é responsável pelas } \\
\text { áreas financeira, contábil, fiscal, compras e almoxarifado, ocupando o cargo de Gerente } \\
\text { Financeiro. }\end{array}$ \\
\hline Entrevistado F & $\begin{array}{l}\text { Possui graduação em Ciências Contábeis pela Universidade de Caxias do Sul e } \\
\text { Especialização em Gestão Empresarial, Controladoria, Finanças e Auditoria e Gestão de } \\
\text { Pessoas pela Fundação Getúlio Vargas. Atualmente é responsável pela área de Recursos } \\
\text { Humanos e Tecnologia da Informação, ocupando o cargo de Gerente Administrativo. }\end{array}$ \\
\hline
\end{tabular}

Fonte: elaborado pela autora com base nas entrevistas (2018).

Com base no roteiro de entrevista, foram elencadas as categorias a seguir, evidenciando a percepção de cada entrevistado e a sua relação com os referenciais teóricos.

\subsection{ENTENDIMENTO SOBRE LIDERANÇA}

$\mathrm{Na}$ maioria das abordagens teóricas estudadas entende-se liderança como a influência sobre as outras pessoas, estimulando de modo a trabalharem com entusiasmo e determinação em busca dos objetivos propostos (BATEMAN; SNELL, 2007; MELLO; ORTEGA, 2012).

Nessa mesma perspectiva, para o entrevistado A, o papel do líder é fundamental na construção do trabalho. O mesmo entende que o líder deve ser seguido e servir de exemplo aos seus liderados, criando um ambiente propício para que as coisas aconteçam naturalmente. 
Para o entrevistado B liderar é "conseguir com que as pessoas que trabalham com o líder façam aquilo que a empresa espera de uma forma natural (.), que entendam que não é apenas uma obrigação, que façam porque acreditam que é importante e se sintam parte daquilo".

Por sua vez, o entrevistado $\mathrm{C}$ destaca que liderar é atingir metas através da sua equipe, o líder é aquele que inspira, realiza feedback e desenvolve as pessoas. Essa perspectiva é muito semelhante à apresentada por Mello e Ortega (2012), na qual enfatizam que as pessoas devem participar da gestão dos negócios, sendo preparadas para compreender como a empresa funciona e como o trabalho de cada um reflete nos resultados atingidos. Para isso, deve-se promover o empowerment das pessoas.

O entrevistado D considera que, para conseguir a confiança da equipe, o líder deve proporcionar as diretrizes e condições de trabalho, demostrando que as suas propostas fazem parte do dia a dia da organização e que são importantes para o desenvolvimento do trabalho.

Na percepção do entrevistado E, liderar exige ter o dom de entender o propósito da organização, repassando-o para sua equipe. O líder precisa fazer com que o grupo confie nele, acompanhando os colaboradores na execução das atividades para o atingimento dos objetivos.

Por fim, para o entrevistado F, liderar significa cuidar das pessoas, entender a necessidade delas (.) compreender a parte humana (.) ter um ponto de equilíbrio entre pessoas e a técnica.

Observa-se que os gestores da empresa possuem uma visão adequada do que é liderar, considerando as bases teóricas utilizadas nesse estudo. Em síntese, na percepção dos entrevistados liderar é ser o exemplo, é fazer o que precisa ser feito e estabelecer metas, fazendo com que as pessoas trabalhem para atingi-las.

\subsection{PERFIL DO LÍDER DA EMPRESA}

Cada empresa apresenta um perfil de liderança que geralmente está relacionado com a cultura organizacional, contemplando características racionais e emocionais (MELLO; ORTEGA, 2012).

O entrevistado A entende que o perfil de líder ideal para a empresa deve ser voltado às mudanças, adequando-se rapidamente as necessidades. Destacou a importância de o líder estar atento à motivação das pessoas, definindo que "o bom líder não precisa ser melhor em tudo, mas precisa entender um pouco de tudo", sendo objetivo e transparente com a equipe.

Para o entrevistado B o líder ideal para empresa é aquele que, além do conhecimento técnico, consegue desenvolver competências relacionadas à gestão de pessoas na área de 
produção, o entrevistado acredita que as lideranças devam ser divididas entre coordenadores da área de gestão de pessoas e com facilitadores que estejam mais voltados para as competências técnicas. Dentro das competências para liderar, o entrevistado entende como as mais importantes: ter paciência e capacidade analítica para tomar decisões. Por sua vez, o entrevistado $\mathrm{C}$ entende que conhecer bem as interfaces do seu processo, o seu papel e as suas responsabilidades é indispensável para um líder atuar na empresa.

$\mathrm{Na}$ mesma linha de pensamento, para o entrevistado $\mathrm{D}$, é indispensável ter o conhecimento do todo, buscando alternativas para chegar ao objetivo proposto pela alta direção. Sendo essencial para este líder ter a capacidade de inovação e visão em longo prazo. Com relação às competências, o entrevistado entende que o líder necessita já ter a característica nata de liderança, para posteriormente ser aprimorada.

Para o entrevistado E, um líder da empresa necessita ter conhecimento do negócio, atitudes e habilidades de gestão. (.) "nossa liderança hoje está muito voltada à tarefa, mas é necessário desenvolver uma visão estratégica, ampla visão de futuro, tendo que se adaptar a necessidade da empresa (.) o nosso líder tem a capacidade, mas precisa ser desenvolvido (.). Para liderar é essencial inspirar confiança, indicar o caminho, oferecendo suporte necessário, ter humildade e trabalhar em equipe proporcionando trocas. Um líder precisa estimular seu autodesenvolvimento e autoconfiança” (ENTREVISTADO E, 2018).

"Para a empresa, o líder tem que ser desenvolvido para questão humana, um cuidado maior com as pessoas, (.) hoje a liderança está pouco comprometida com o todo, mas sim em seu interesse próprio. Ou seja, precisa ser aliada a questão técnica com a gestão de pessoas". Para liderar, o entrevistado destaca que deve haver competência, comunicação e a disposição para o diálogo. Também acredita que o líder deve dar feedbacks constantes, ser o exemplo e ter compromisso, executando o que foi prometido (ENTREVISTADO F, 2018).

O líder deve ter zelo e cuidado com as pessoas, estar próximo da equipe, capacitar e reter talentos, buscar resultados, ser humilde e saber ouvir. Essas são características essenciais para o desenvolvimento e desempenho de sua equipe. De acordo com essa visão, Fernandes (2015) destaca que o melhor líder é aquele que oferece o seu melhor e tem humildade para receber o melhor dos outros, sendo capaz de formar e manter uma equipe de alto desempenho, com funcionários independentes e protagonistas do próprio sucesso.

Observa-se que no caso da empresa, a maioria dos gestores salientaram os aspectos humanos inerentes à liderança, porém também pontuaram a necessidade de ter a competência técnica para executar as atividades, em função do modelo de negócio da empresa, que exige o 
conhecimento técnico. Outro ponto de extrema importância e que surgiu na percepção da maioria dos entrevistados, é a necessidade de ter a visão sistêmica dos negócios.

\subsection{PERCEPÇÃO SOBRE COMUNICAÇÃO DE LIDERANÇA}

A comunicação dentro das organizações auxilia no alcance dos resultados e, quando bem executada, contribui na integração entre líderes e liderados. Sendo que o processo somente é bem-sucedido quando o funcionário recebe, compreende e interpreta a mensagem de forma correta e objetiva.

O entrevistado A destaca, com relação à comunicação interna, a falta de uniformidade nas informações da empresa. "em 99\% dos lugares existem problemas de comunicação (.) o problema é que sabemos falar, mas não sabemos comunicar" (ENTREVISTADO A, 2018).

O entrevistado B exemplifica que a comunicação interna na empresa é falha “(.) inclusive da minha parte, muitas vezes saio de reuniões com a direção (.) se perde muito daquilo que é falado na reunião até repassar para a equipe", o mesmo entende que talvez fosse necessária uma metodologia ou treinamentos específicos para conduzir a comunicação. Enquanto líder, utiliza meios de comunicação próprios "criei grupos de WhatsApp para escrever para meus liderados, assim não corro o risco de esquecer", também citou que o uso da ferramenta Trello, que é um sistema de quadro virtual para gerenciamento de tarefas, que vem o auxiliando para administrar a organização do dia a dia, facilitando a rotina e a comunicação.

Quanto à comunicação, o entrevistado $\mathrm{C}$ destaca que ainda existem muitos ruídos, justamente por faltar clareza em muitas definições, sejam elas institucionais ou relativas às atividades diárias. "(.) é necessário um ambiente aberto, sem muros ou paredes, uma comunicação assertiva" (ENTREVISTADO C, 2018).

O entrevistado D pontua que a comunicação é falha, existem muitos gaps no processo, “(.) muitas vezes a liderança distorce, falta treinamento, às vezes não entendem, não perguntam, e, depois quando transmitem, fazem da forma equivocada (.)", o entrevistado entende que algumas comunicações deveriam ser feitas diretamente pelo setor de Recursos Humanos, não envolvendo a liderança, assim seria mais uniforme. $O$ entrevistado informou que atua diretamente com sua equipe, promovendo a comunicação no dia a dia, conforme a demanda.

Segundo o entrevistado E, “(.) precisamos desenvolver a capacidade de saber ouvir e interpretar para assim poder comunicar, se tem dúvidas buscar mais informações (.) vejo que acontece muitas vezes de presumir e levar adiante dessa forma (.) a comunicação é falha, pois 


\section{ARTIGO}

INOVAÇÃo

muitas vezes ela para e não acontece (.) quem recebe também necessita saber ouvir para entender a comunicação que está recebendo".

$\mathrm{O}$ entrevistado F destaca que atualmente o setor de recursos humanos tem o papel de atuar com a liderança na divulgação das informações, orientando o líder para que as informações sejam repassadas corretamente, porém ainda existem muitas dificuldades em como isso acontece, “(.) hoje a liderança ainda está muito voltada para tarefa, e por isso muitas vezes o líder entende que não é necessário repassar a informação”. Também foi evidenciado “(.) que a comunicação vai muito além de enviar um e-mail, colocar no mural, mas também checar que a pessoa entendeu a mensagem (.) ainda a comunicação melhor é aquela onde reunimos as pessoas e passamos a informação uniforme" (ENTREVISTADO F, 2018).

Percebe-se nessa etapa de entrevistas que os gestores reconhecem a necessidade de melhorar o processo de comunicação, pois atualmente ela ocorre com muitas falhas e distorções até chegar a quem se destina. Fica claro nesta questão a necessidade de melhorar a capacidade de comunicação da empresa, focando na liderança, a qual hoje é responsável por retransmitir as informações oriundas da direção. Destaca-se ainda que muitos dos entrevistados

delegam a responsabilidade da comunicação à área de Recursos Humanos, enquanto essa seria uma atividade designada aos líderes da empresa (BRUM, 2017).

\subsection{PERCEPÇÃO SOBRE FEEDBACK}

Quando questionados sobre o processo de feedback, o entrevistado A relata que esse é um ponto a ser desenvolvido por ele, pois em suas experiências, os retornos e devoluções foram sempre muito baixos. Entende que a forma estruturada que existe hoje não é a ideal e que o "feedback é o que se tem na hora (.) sendo uma forma de construção (.) temos que incentivar mais momentos fora da formalização". Introduzir no dia a dia, devoluções com agradecimentos, faz com que nos momentos que seja necessário a cobrança, essa seja entendida com maior facilidade.

O entrevistado B relata que realiza a avaliação de desempenho, anualmente, para realizar o feedback com sua equipe. Entretanto, em sua percepção, falta um preparo para esse trabalho, pois existem falhas nesse processo "nós temos dificuldade de realizar (.) todo ano recebemos treinamento (.) talvez isso não esteja sendo efetivo (.) temos que preparar melhor nossos líderes, mas também quem está recebendo".

Relacionado ao feedback, o entrevistado C entende que sensibilizar através de evidências, cases, experiências é a melhor forma de atuar. Para o entrevistado D “a liderança 
não está preparada para dar feedback", ele enquanto líder procura dar feedbacks além do estabelecido pela empresa na avaliação de desempenho, que ocorre uma vez por ano, ressaltando coisas pontuais do dia a dia e elencando pontos positivos e negativos.

O entrevistado E entende que no feedback devem ser abordados os aspectos negativos e positivos, evidenciando oportunidades de melhoria, sendo pontual no momento em que ocorrem os fatos.

Com relação ao feedback o entrevistado $\mathrm{F}$ destaca como sendo muito importante para o desenvolvimento da equipe, proporcionando o crescimento individual de cada colaborador. Do mesmo modo, também explicou que para os líderes ainda falta o desenvolvimento para essas devolutivas.

O feedback é um processo que consiste no provimento de informação à uma pessoa sobre o seu desempenho, conduta, ou ação executada. O objetivo é orientar ou estimular ações de melhoria. Contudo, o momento de feedback é uma troca entre as partes onde são abordados pontos positivos e de melhoria. Quando se trata de uma crítica, cabe ao receptor analisar a importância deste diálogo para a melhoria de suas atividades. Isso melhora o autoconhecimento, reformula as atitudes e faz perceber melhor nossos pontos a desenvolver.

Da mesma forma, Knapik (2008) destaca que o feedback pode ser uma realimentação positiva e um reforço para o desempenho desejado. Demonstrar uma comunicação clara, precisa e objetiva, pode identificar uma falha no processo de comunicação, um comportamento indesejado ou inadequado. Nesses casos, o feedback pode enfrentar certas resistências da parte de quem recebe as informações.

\subsection{DESENVOLVIMENTO DE NOVOS LÍDERES}

Para o desenvolvimento de lideranças, o entrevistado A destaca esse aspecto como sendo muito importante e relata que tentou fazer com que as pessoas tivessem o desejo de assumir a liderança. Em todas as suas experiências teve casos onde ele assumiu novos postos e teve sucessores dentro da sua equipe.

Quando questionado sobre um programa de desenvolvimento de lideranças, menciona que o mais importante é identificar se os líderes atuais e possíveis sucessores têm habilidades com gestão de pessoas e se a pessoa está apta a ir além da sua capacidade técnica "(.) transformar em líder para valorizar é o pior erro que tem". O entrevistado A entende também ser importante criar um programa que valorize quem tem capacidade técnica, sem ser apenas 
promovendo este profissional para um cargo de liderança, muitas vezes com este movimento a empresa além de não ganhar um líder, perde um profissional de alto desempenho técnico.

Com relação ao desenvolvimento de novas lideranças, o entrevistado B destaca que já tem pessoas sendo treinadas para sucessão em sua equipe. Demonstra uma preocupação em aliar o conhecimento técnico com a gestão de pessoas. Destacou também que é importante avaliar a capacidade de liderança, pois entende que dificilmente esta será desenvolvida se a pessoa não tiver as características necessárias.

Tratando-se de um programa de desenvolvimento de lideranças, o entrevistado B salienta que a empresa deve identificar quais os atuais e futuros líderes que serão desenvolvidos, moldando de acordo com a necessidade da empresa. Essa percepção é muito semelhante à apresentada pelo autor Charan (2008).

Relacionado ao desenvolvimento de lideranças, o entrevistado $\mathrm{C}$ comenta que o processo de sucessão de líderes da empresa deveria ser mais aberto, transparente e impessoal. "Tento, dentro das condições, seguir de forma construtiva e positiva a prática do aprendizado, que oportunidades sempre existem para quem busca o conhecimento". Para um programa de desenvolvimento de líderes o entrevistado pontua que é imprescindível a prática do diálogo, planejamento, organização e o conhecimento.

Com relação ao desenvolvimento de novos líderes, o entrevistado D observa o empenho de cada colaborador, ou seja, o quanto ele busca se autodesenvolver, cercando-se de conhecimentos técnicos e habilidades de gestão. Após isso, proporciona dentro da equipe as etapas para que o colaborador se aperfeiçoe, atendendo as expectativas da empresa.

O entrevistado E sempre procura desenvolver novos líderes, considera importante ter na equipe pessoas capazes de assumir esse posto quando uma necessidade surgir. Relacionado ao programa de desenvolvimento de líderes considera importante abordar temas específicos de comunicação, o que está bastante deficitário entre a liderança.

Para o entrevistado F, desenvolver líderes é essencial para a continuidade do negócio. Atualmente utiliza-se da observação para verificar o quanto a pessoa está engajada com as suas entregas e os seus relacionamentos. Quanto ao programa de desenvolvimento de líderes, considera importante abordar relacionamentos, comunicação e feedback, sendo personalizados a necessidade da empresa.

Por meio da pesquisa qualitativa realizada com os executivos da empresa, foi possível identificar o perfil da liderança e as necessidades de melhoria para o tema proposto.

Hoje existem muitas falhas no processo de comunicação no que diz respeito à liderança. Atualmente, os líderes estão voltados à tarefa e não têm seu potencial explorado para a 
estratégia, necessitando desenvolvimento gerencial. Desta forma, o ideal é a realização de um programa de desenvolvimento de líderes, voltado para as necessidades da empresa, contemplando a atual liderança e possíveis sucessores, para que assim estejam devidamente preparados.

No atual cenário, o programa deve abordar fortemente as questões relativas à comunicação e ao feedback, necessidades apontadas por todos gestores nas entrevistas. Também é essencial abordar as questões estratégicas, para desenvolver nos novos líderes essa percepção, que hoje é diretamente voltada a execução.

Tornar líderes voltados à tarefa em líderes colaborativos é o objetivo do programa de desenvolvimento de lideranças da empresa. Kouzes e Posner (2008) destacam que qualquer talento pode ser reforçado, alimentado e galvanizado, havendo motivação e desejo, aliado a prática dofeedback, modelos de gestão e treinamentos nessa mesma perspectiva, Charan (2008) diz que as empresas podem desenvolver líderes, desde que tenham claro quais são os conhecimentos que o líder deve ter e o que é necessário para desenvolver cada um.

\section{CONSIDERAÇÕES FINAIS}

O principal diferencial competitivo para as empresas são as pessoas com adaptabilidade, conhecimento, visão do negócio, inteligentes emocionalmente, proativas e comprometidas com resultados, tendo nos líderes, o seu incentivador.

De acordo com o referencial teórico pesquisado, identificou-se que as organizações necessitam de líderes que definam estratégias, que sejam comunicativos e que engajem as pessoas rumo ao mesmo objetivo. A comunicação é essencial e, quando não ocorre, os problemas logo surgem, podendo apresentar funcionários desmotivados, gerando insatisfação e com isso, a baixa produtividade, sem o alcance das metas e objetivos.

Uma comunicação clara, objetiva e eficaz é fundamental para o sucesso da organização. Os líderes necessitam se comunicar diária e constantemente com seus liderados e, nesse processo, é imprescindível que a equipe possa relacionar o comportamento do líder com seu discurso.

O objetivo principal do estudo era identificar a percepção dos gestores sobre a liderança e a importância da comunicação para atingir os objetivos propostos pela empresa e esse objetivo foi atendido. Por meio do estudo, percebeu-se que os gestores entrevistados possuem uma visão clara sobre o que é liderar e a importância de estabelecer uma comunicação assertiva junto à equipe. Todavia, nota-se que os próprios gestores percebem a necessidade de desenvolvimento 
de competências de liderança, entre as quais a visão sistêmica, aprimoramento da comunicação e o processo de feedback, que não deve ocorrer somente na avaliação de desempenho.

Durante a pesquisa foi evidenciado que a atual liderança da empresa está voltada para a tarefa, realizando um papel mais operacional do que estratégico, tendo líderes mais técnicos. Com o seu crescimento e posicionamento no mercado, a empresa tem como necessidade futura desenvolver líderes voltados para a gestão, que apresentem o entendimento da visão estratégica do negócio (visão sistêmica).

O programa de desenvolvimento de líderes da empresa virá ao encontro dessas necessidades, desenvolvendo os atuais e futuros gestores, para uma visão estratégica, voltada para a gestão e focada nos resultados estabelecidos neste programa, de acordo com as necessidades apontadas pelos gestores, é fundamental abordar principalmente os temas de comunicação e feedback, assuntos mais críticos evidenciados pelas pesquisas de clima analisadas, bem como nas entrevistas com os gestores.

Esse estudo apresenta como limitação de pesquisa o fato de não ter contemplado todos os gestores da empresa, apenas os principais, sendo os gerentes, em função do número de integrantes da equipe de líderes ser extenso e composto por coordenadores, líderes e facilitadores. Outra limitação consiste na abordagem metodológica, pois não foi possível, devido ao tempo disponível, realizar uma pesquisa quantitativa para validar os resultados da pesquisa qualitativa.

Para estudos futuros, recomenda-se aplicar a mesma pesquisa para todos os níveis de gestores da empresa, bem como desenvolver uma pesquisa que busque analisar como os funcionários percebem a liderança da organização e como percebem que a comunicação e o feedback podem ser aprimorados. Além disso, pode-se investigar qual é o impacto do papel dos líderes no clima organizacional e a eficácia dos canais de comunicação utilizados atualmente, assim melhorando e desenvolvendo cada vez mais a empresa e seus funcionários. 


\section{ARTIGO}

INOVAÇÃo

\section{REFERÊNCIAS}

AAKER, D.A; KUMAR, V; DAY, G. S. Marketing Research. 9. ed. Nova York: John Wiley \& Sons, 2007.

ACEVEDO, C. R.; NOHARA, J. J. Monografia no curso de Administração: guia completo de conteúdo e forma. São Paulo: Atlas, 2007.

BALDWIN, T.; RUBIN, R.; BOOMER, W. Desenvolvimento de habilidades gerenciais. Rio de Janeiro: Elsevier, 2008.

BATEMAN, T. S.; SNELL, S. A. Administração: liderança e colaboração no mundo competitivo. São Paulo: McGraw-Hill, 2007.

BLANCHARD, K. Liderança de Alto Nível: como criar e liderar organizações de alto desempenho. Bookman, 2011.

BRUM, A. de M. Endomarketing Estratégico: Como transformar líderes em comunicadores e empregados em seguidores. São Paulo: Integrare, 2017.

BERGAMINI, C. W. O líder eficaz. São Paulo: Atlas, 2009.

CHARAN, R. O líder criador de líderes. Rio de Janeiro: Elsevier, 2008.

COHEN, A.; FINK, S. Comportamento organizacional: conceitos e estudos de caso. Rio de Janeiro: Campus, 2003.

CORTELLA, S. M.; MUSSAK, E. Liderança em Foco. Campinas: M. R. Comacchia Livraria e Editora Ltda., 2016.

FERNANDES, M. Felicidade dá Lucro. São Paulo: Schwarcz S.A, 2015.

GIL, A. C. Gestão de pessoas: enfoque nos papéis profissionais. São Paulo: Atlas, 2001.

HUNTER, J. C. O monge e o executivo: uma história sobre a essência da liderança. Rio de Janeiro: Sextante, 2004.

KNAPIK, J. Gestão de Pessoas e Talentos. Curitiba: IBPEX, 2008.

KOUZES, J.; POSNER, B. O novo desafio da liderança. Rio de Janeiro: Elsevier, 2008.

MADRUGA, R. Triunfo da liderança: práticas, estratégias e técnicas diárias para desenvolver Líderes de alta performance. 2. ed. São Paulo: Atlas, 2014.

MARCONI, M. de A.; LAKATOS, E. M. Técnicas de pesquisa: planejamento e execução de pesquisas, amostragens e técnicas de pesquisa, elaboração, análise e interpretação de dados. 7 . ed. São Paulo: Atlas, 2008.

MAXIMIANO, A. C. A. Introdução à Administração. 8. ed. São Paulo: Atlas, 2011.

MAXWELL, J. C. A arte de formar líderes: como transformar colaboradores em empreendedores. Rio de Janeiro: Editora S.A, 2011. 
MELO, E. A. de A. Liderança gerencial. In: SIQUEIRA, M. M. M. Novas medidas do comportamento organizacional. Porto Alegre: Artmed, 2014.

MELLO, J. B. de; ORTEGA, M. Práticas de gestão empresarial de alta performance. São Paulo: Nova Cultural, 2012.

MOSCOVICI, F. Desenvolvimento Interpessoal: treinamento em grupo. 15. ed. Rio de janeiro: José Olympio, 2005.

MOTTA, P. R. A ciencia e a arte de ser dirigente. 8. ed. Rio de Janeiro: Record, 1997.

OLIVEIRA, D. P. R. de. Teoria geral da administração: uma abordagem prática. 2. ed. São Paulo: Atlas, 2010.

PRODANOV, C. C.; FREITAS E. C. Metodologia do trabalho cientifico: Métodos e Técnicas. Novo Hamburgo: Feevale, 2013.

ROESCH, S. M. A. Projeto de estágio e pesquisa em administração: guia para estágios, trabalho de conclusão, dissertações e estudos de caso. 3. ed. São Paulo: Atlas, 2006.

RUTTER, M.; ABREU, S. A. de. Pesquisa de mercado. São Paulo: Ática, 2003.

SELMAN, J. Liderança. São Paulo: Pearson Prentice Hall, 2010.

SOARES, M. T. R. Liderança e desenvolvimento de equipes. 1. ed. São Paulo: Pearson Educaion do Brasil, 2015.

STAKE, R. E. Pesquisa qualitativa: estudando como as coisas funcionam. Porto Alegre: Penso, 2011.

VERGARA, S. C. Projetos e relatórios de pesquisa em Administração. 3. ed. São Paulo: Atlas, 2000.

WAGNER, J. A.; HOLLENBECK, J. R. Comportamento Organizacional: criando vantagem competitiva. 2. ed. São Paulo: Saraiva 2009.

WALKER, R. Gerenciamento estratégico de comunicação para líderes. São Paulo: Cengage Learning, 2015.

YIN, R. K. Estudo de caso: planejamento e métodos. 3. ed. Porto Alegre: Bookman, 2005.

YIN, R. K. Estudo de caso: planejamento e métodos. 4. ed. Porto Alegre: Bookman, 2010. 